\title{
A Selective Pulmonary Thrombosis Associated with Sepsis-Induced Disseminated Intravascular Coagulation
}

\author{
Masayuki Ainara, Tsugio NakazawA*, Kunio Dobashi, Takashi JoshitA**, \\ Masaru KoJIMA**, Masayuki OnAI*** and Masatomo Mori
}

\begin{abstract}
Disseminated intravascular coagulation (DIC) is a pathologic condition associated with critical illnesses, including sepsis. Recent studies have suggested that endogenous cytokines and leukocytes are involved in major roles of its pathophysiology. We report a case of sepsis-induced DIC due to pneumonia that was associated with diffuse and selective thrombosis in pulmonary arteries, yielding to sudden death from pulmonary massive embolism. This report suggests that the selective and lethal pulmonary thromboembolism progresses under the standard therapies in sepsisinduced DIC.
\end{abstract}

(Internal Medicine 36: 97-101, 1997)

Key words: inflammatory mediators, leukocytes, selective pulmonary thromboembolism, septicemia, standard therapies, widespread intravascular coagulation

\section{Introduction}

Disseminated intravascular coagulation (DIC) is characterized by the slow formation of fibrin in the microcirculation and the development of concomitant fibrinolysis. It is always observed secondary to various critical illnesses (1).

DIC was first reported in a case of fatal hemorrhagic diathesis with premature detachment of the placenta (2), in which it was thought that the pathogenic mechanism was the exposure of blood to tissue factor (thromboplastin) in the placenta and amnionic fluid, causing systemic microthrombi formation via the extrinsic pathway and resulting in microcirculatory disturbances and organ dysfunction $(3,4)$.

DIC is also common in patients with various types of infections such as sepsis (5).

However, the infection-induced DIC seems to have different features from that of DIC occurring as an obstetric complication. Recent studies have suggested that infectious agents such as endotoxin, endogenous cytokines and leukocytes are involved in its pathophysiology (6-12).

We report a case of DIC with sepsis due to pneumonia that lead to sudden death even though standard therapies were certainly effective. The autopsy findings revealed that the cause of death was right pulmonary massive embolism based on the diffuse and selective thrombosis in the pulmonary arteries.

\section{Case Report}

A 23-year-old man was admitted to the hospital in May 1995, because of a 7-day history of low grade fever, a 3-day history of productive cough, and chest pain on the right side without any evidence of respiratory distress. He had no lung disease and had been generally healthy prior to the onset of this illness.

Physical examination disclosed a temperature of $37,0^{\circ} \mathrm{C}$, and inspiratory moist crackles in the right lung. No bleeding or palpable lymphadenopathy was found and the results of neurologic examination were normal. There was no varicose vein in extremities.

The chest roentgenogram obtained on the day of admission demonstrated infiltrate and pleural effusion at the right lung base (Fig. 1). A computed tomographic scan (CT scan) of the chest confirmed these findings and also revealed slight infiltrate at the left lung base. The electrocardiogram (ECG) was normal.

Laboratory findings as shown in Table 1 indicated leukocytosis with eosinophilia, high level of C-reactive protein (CRP), fibrinogen and fibrin degradation products (FDP) and D-dimer, low platelet count, single deficiency of factor $\mathrm{V}$, and

From the First Department of Internal Medicine, Gunma University, School of Medicine, Maebashi, *the Department of Physical Therapy, Gunma University, School of Health Sciences, Maebashi, **the Department of Laboratory Medicine and Clinical Laboratory Center, Gunma University, School of Medicine, Maebashi and ***the Department of Internal Medicine, Tcho Hospital, Kasakake

Received for publication July 3, 1996; Accepted for publication November 25, 1996

Reprint requests should be addressed to Dr. Masayuki Aihara, the First Department of Internal Medicine, Gunma University, School of Medicine, 3-39-15 Showamachi, Maebashi, Gunma 371 

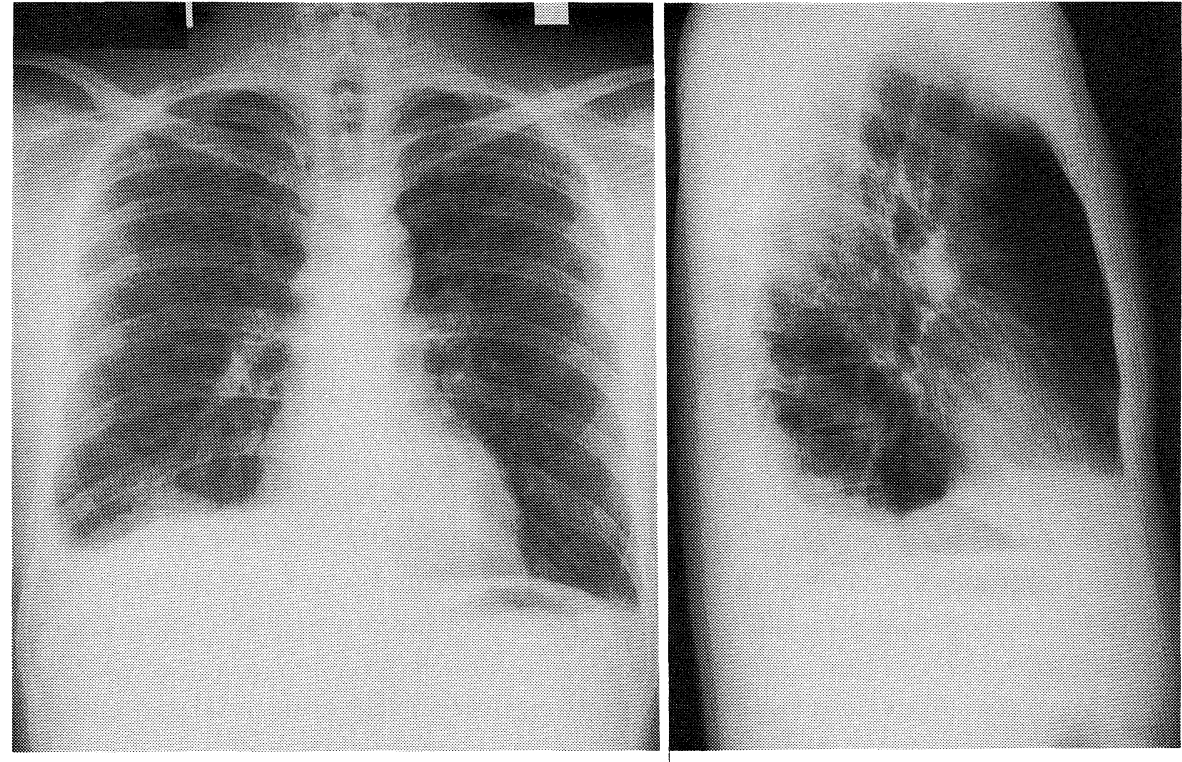

Figure 1. The chest radiograph at the time of hospital admission shows an infiltrate and a pleural effusion at the right lung base.

Table 1. Laboratory Findings

\begin{tabular}{|c|c|c|c|c|}
\hline \multicolumn{2}{|l|}{ Hematological study } & Blood chemistry & \multirow{2}{*}{$\begin{array}{l}\text { BUN } \\
\text { creatinine }\end{array}$} & $14.5 \mathrm{mg} / \mathrm{dl}$ \\
\hline White blood cells & $11,640 / \mathrm{mm}^{3}$ & $6.9 \mathrm{~g} / \mathrm{dl}$ & & $0.9 \mathrm{mg} / \mathrm{dl}$ \\
\hline Neutrophil & $58 \%$ & $4.0 \mathrm{~g} / \mathrm{dl}$ & Uric acid & $4.0 \mathrm{mg} / \mathrm{dl}$ \\
\hline Lymphocyte & $8 \%$ & $0.78 \mathrm{mg} / \mathrm{dl}$ & $\mathrm{Na}$ & $143 \mathrm{mEq} / \mathrm{l}$ \\
\hline Monocyte & $8 \%$ & $115 \mathrm{IU} / l$ & $\mathrm{~K}$ & $4.5 \mathrm{mEq} / \mathrm{l}$ \\
\hline Eosinophil & $26 \%$ & $164 \mathrm{IU} / l$ & $\mathrm{Cl}$ & $105 \mathrm{mEq} / \mathrm{l}$ \\
\hline Basophil & $0 \%$ & $791 \mathrm{IU} / l$ & S-Amylase & $54 \mathrm{IU} / l$ \\
\hline $\mathrm{RBC}$ & $492 \times 10^{4} / \mathrm{mm}^{3}$ & $556 \mathrm{IU} / l$ & FBS & $119 \mathrm{mg} / \mathrm{dl}$ \\
\hline Hemoglobin & $14.5 \mathrm{~g} / \mathrm{ml}$ & $43 \mathrm{IU} / l$ & \multirow[b]{2}{*}{ AT-III activity } & \\
\hline Hematocrit & $44.3 \%$ & $15.6 \mathrm{mg} / \mathrm{dl}$ & & $139 \%(84-138)$ \\
\hline Platelets & $3.6 / \mathrm{mm}^{3}$ & hepaplastin test $\quad 100 \%$ & & \\
\hline \multicolumn{2}{|c|}{ Erythrocyte sedimentation rate $19 \mathrm{~mm} / \mathrm{hr}$} & FDP $\quad 80 \mu \mathrm{g} / \mathrm{ml}(<40)$ & \multicolumn{2}{|c|}{ Coagulation factors } \\
\hline anti-nuclear antibody & $(-)$ & D-dimer $33.1 \mu \mathrm{g} / \mathrm{ml}(<0.75)$ & \multirow{5}{*}{$\begin{array}{ll}\text { Factor } & \text { V } \\
& \text { VII } \\
& \text { IX } \\
& \text { X }\end{array}$} & $62 \%(75-120)$ \\
\hline anti-DNA antibody & $(-)$ & Fibrinogen $\quad 189 \mathrm{mg} / \mathrm{ml}$ & & I $92 \%(80-115)$ \\
\hline rheumatoid factor & $(-)$ & bleeding time & & $109 \%(80-120)$ \\
\hline $\mathrm{CH}_{50}$ & $48 \mathrm{U} / \mathrm{ml}(29-48)$ & $35.7 \mathrm{sec}$ & & $103 \%(80-115)$ \\
\hline $\operatorname{IgE}$ & $810 \mathrm{U} / \mathrm{ml}$ & $14.9 \sec 59 \%$ & & \\
\hline Serological tests & & Mantoux reaction & & \\
\hline STS & $(-)$ & & & \\
\hline $\mathrm{HBs} \mathrm{Ag}$ & $(-)$ & sputum culture & & \\
\hline $\mathrm{HCV} \mathrm{Ab}$ & $(-)$ & & & \\
\hline
\end{tabular}

ALT: alanine aminotransferase, AST: aspartate aminotransferase, APTT: activated partial thromboplastin time, BUN: blood urea nitrogen, $\mathrm{CH}_{50}: 50 \%$ hemolytic unit of complement, FBS: fasting blood sugar, FDP: fibrinogen and fibrin degradation products, PT: prothrombin time, STS: serological test for syphilis.

liver dysfunction (elevation of the hepatic enzymes) with negative serological tests for hepatitis type $\mathrm{B}$ and $\mathrm{C}$ virus. The bleeding time, activated partial thromboplastin time (APTT) prothrombin time (PT), level of fibrinogen, activity of antithrombin-III(AT-III), the erythrocyte sedimentation rate (ESR), hepaplastin test were within normal range. High levels of 
alkaline phosphatase (ALP), lactate dehydrogenase (LDH), and immunoglobulin E (IgE) were shown. Negative results were obtained in the tests for anti-nuclear antibody, anti-DNA antibody, and rheumatoid factor. No pathological microorganism was cultured from the sputum.

Following the institution of aggressive medical treatment with intravenous and oral administration of antibiotics, anticoagulation, and other supportive therapies, the severity of his symptoms diminished, his temperature was reduced to the normal level, and the intensity of inflammation was obviously decreased by hospital day 7 . A chest roentgenogram obtained on day 8 showed improvement of the infiltrates and pleural effusion. Furthermore, on day 9, the level of FDP was decreased to $40 \mu \mathrm{g} / \mathrm{ml}$ and the platelet count was increased to $48 \times 10^{3} /$ $\mathrm{mm}^{3}$. During this hospitalization, the patient was generally active and had no dyspnea on either rest or movement, no general fatigue, and no bleeding.

On the morning of hospital day 10 , the patient suddenly went into cardiopulmonary arrest in the bed. Even though cardiopulmonary resuscitation was performed immediately and me-

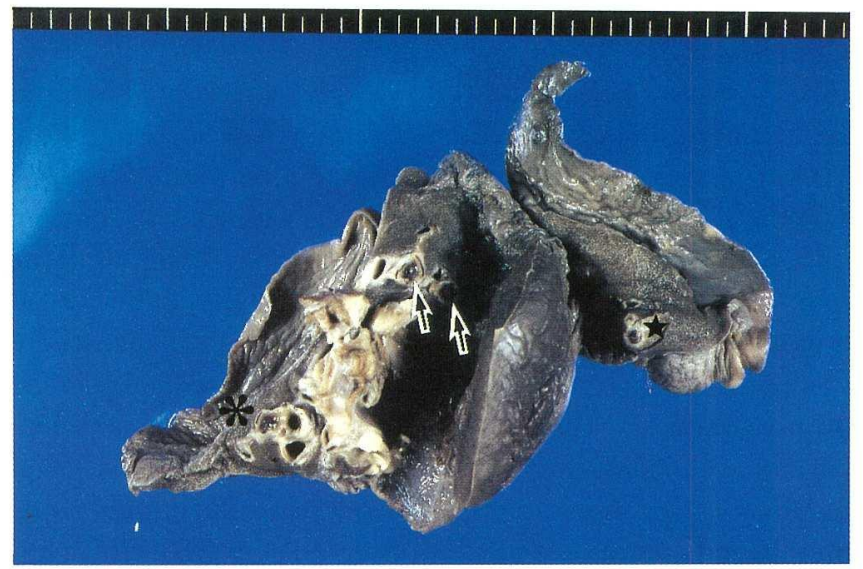

Figure 2. Pulmonary massive embolism. The right pulmonary artery was occluded by thrombi in the superior truncus $(\star)$, in the middle lobe artery $(\leftarrow)$ which was cut during autopsy, and in the basal truncus $(*)$. These findings were absent in the left lung.
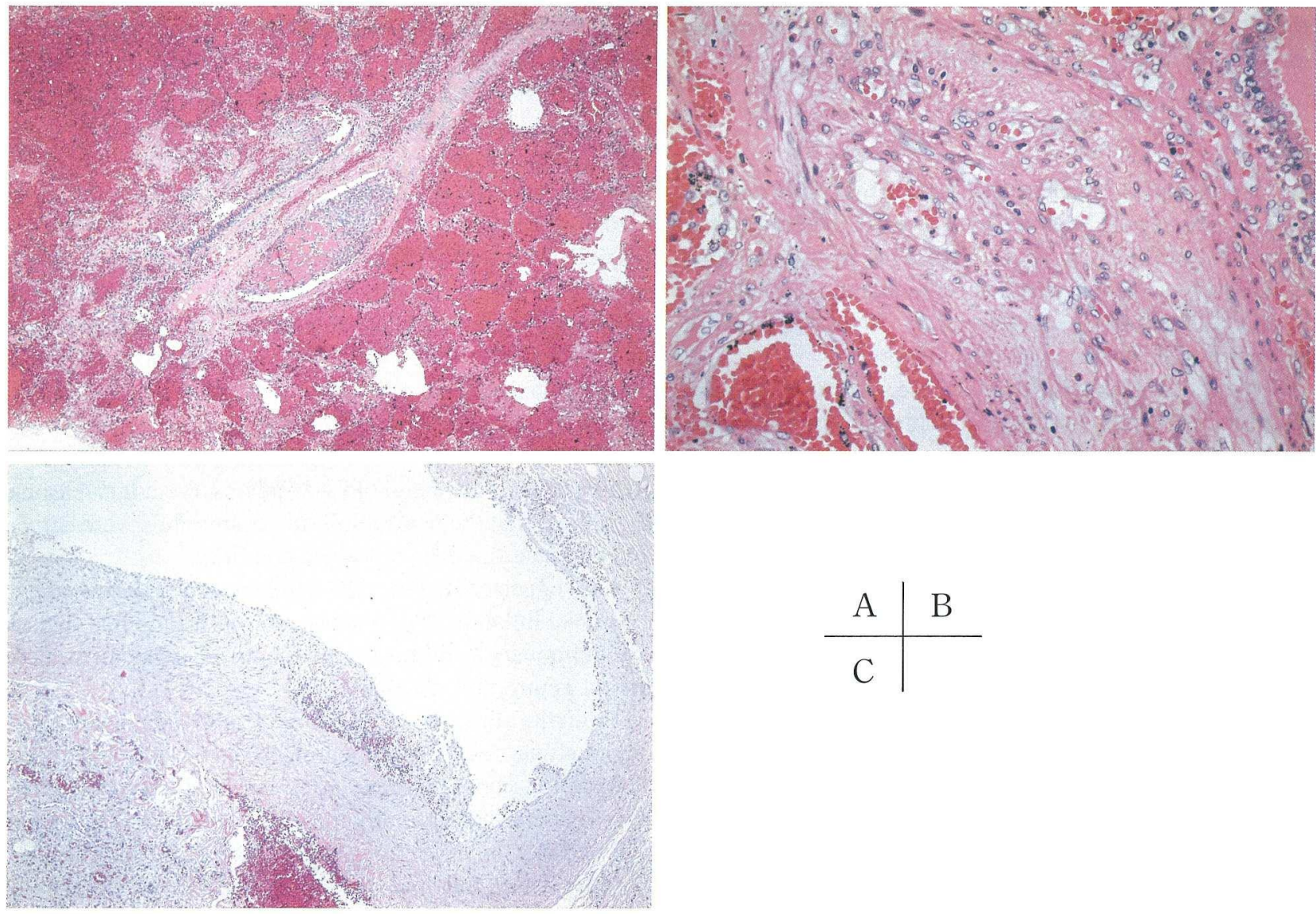

Figure 3. A) Thrombosis in pulmonary artery surrounded with pulmonary hemorrhage. In the center of this figure, a thrombus is seen to occlude the pulmonary artery (Hematoxylin and eosin (HE), original magnification $\times 33$ ). B) A thrombosis in the pulmonary artery that demonstrates organization and recanalization of the pulmonary thrombus (HE, original magnification $\times 165$ ). C) The endothelium of the pulmonary artery was damaged without the occlusion of thrombus. This change is thought to be fresh $(\mathrm{HE}$, original magnification $\times 33$ ). 
chanical ventilatory support was started, the patient died from acute respiratory failure.

A CT scan of the head following his death indicated no abnormality, such as intracranial hemorrhage or infarction. With the consent to postmortem examination of the chest and abdomen, the autopsy revealed embolic occlusion by thrombi in superior truncus, middle lobe artery, and basal truncus of the right pulmonary artery (Fig. 2). Macroscopically, there was no thrombus in the heart, coronary arteries, and central vein. There was no thrombophlebitis in peripheral veins, especially in the lower extremities. The histological findings included a selective and widespread thrombosis in the pulmonary arteries (Fig. $3 \mathrm{~A}-\mathrm{C}$ ). Furthermore, organization and recanalization in some thrombi and microthrombi were observed (Fig. 3B). However, there was no ischemic necrosis of the lung substance within the area of hemorrhage in both lungs. Such areas of thrombosis or hemorrhage were not observed in any other structure including the kidney, spleen, liver, heart, coronary artery, and aorta. Myocardial infarction was not detected.

The resolution and organization with Masson body of the pneumonia were seen in both lung bases. There was no eosinophilic infiltration in the lungs, myocardium, coronary artery, or other examined organs. Multiple microabscesses in the liver and the infected spleen were observed. There was no other infectious foci except for the resolved pneumonia.

\section{Discussion}

DIC occurs most frequently in association with critical illnesses such as sepsis, liver disease, shock, cancer, obstetric complications, and burns. Recently, sepsis has been interpreted as an inflammatory response of the host to infection rather than the direct effect of microbial aggression. The mechanism of sepsis-induced DIC has been actively examined.

According to the clinical course, laboratory and radiographical findings, autopsy, and histological examinations, it was suggested that this patient developed a systemic infection (sepsis) originating in the pneumonia, and DIC, or at least the stage preceding DIC (pre-DIC) (13).

On the other hand, liver injury due to sepsis was indicated. However, the participation of liver dysfunction in the induction of DIC was excluded, because of the absence of the prolongation of the APTT and PT, the normal level of the AT-III and coagulation factors (factors VII, IX, and X) which are synthesized in the liver, and normal hepaplastin test. Thus, we considered that this patient already had a sepsis-induced DIC as of the day of admission.

The autopsy indicated a massive embolism in the right pulmonary artery, and the histological findings included widespread and selective thrombosis in the bilateral pulmonary arteries. Detailed examinations revealed that organization and recanalization were observed in some thrombi, and suggested that the formation of the oldest thrombi had occurred within about one month, and the latest one within a few days, before his death.

Primary pulmonary hypertension $(\mathrm{PPH})$ was excluded in this case in view of the clinical course and the normal ECG findings without any evidence of right atrial and ventricular enlargement. It is unreasonable to suppose that $\mathrm{PPH}$ progressed rapidly within about one month as a complication. Thrombotic thrombocytopenic purpura (TTP) did not seem to apply in this case, owing to the absence of any of systemic thrombosis, anemia, renal dysfunction, purpura, and neurological signs. Hypereosinophilic syndrome (HES) also did not seem to apply in this case, due to the absence of eosinophilic infiltration in the affected organs such as the lung, liver, and spleen. Acute cerebral hemorrhage was denied as the cause of death of this patient based on the normal findings of postmortem head CT scan, and acute myocardial infarction was also denied by the normal macro- and microscopic findings of the heart and coronary artery.

Therefore, it was concluded that sudden death ensued from right pulmonary massive embolism by thrombi from unknown origin, and that the diffuse and selective thrombosis in the pulmonary arteries had progressed as a complication of the sepsis-induced DIC. At necropsy of patients with DIC, the reported incidence of macroscopic and microscopic pulmonary thromboembolism is $58.6 \%$ and $51.7 \%$, respectively (14). However, there is no report concerning diffuse and selective thrombosis in the pulmonary arteries complicated by sepsisinduced DIC.

Recent studies have suggested that the endogenous inflammatory mediators released from activated leukocytes in sepsis $(11,15-18)$, are capable of inducing DIC without the influx of tissue factor $(15,19)$. Moreover, it was suggested that these mediators activate neutrophils and endothelial cells, which may result in the injury of the endothelial cells by the neutrophils in sepsis $(12,20-23)$. Another study demonstrated that the neutrophil activation contributes to respiratory failure and mortality in patients with DIC (24). These observations suggest that the neutrophils activated in sepsis may cause systemic endothelial injury, especially in a pulmonary arterial system.

In the present case, increased counts for neutrophils and eosinophils in peripheral blood were observed. It is reasonable to suppose that the neutrophils and eosinophils were activated and circulated in this pathologic condition.

It is suggested that the DIC in this patient was caused by the excessive inflammatory response to sepsis, and that the selective pulmonary thrombosis was mainly attributed to the activation of neutrophils in sepsis.

From the clinical course, it was clear that the treatment was obviously successful in alleviating the underlying infection and coagulation abnormalities. However, it failed to prevent the development of pulmonary thromboembolism. Quezado et al reported that multiple clinical trials of anti-endotoxin- and anticytokine-based therapies for sepsis failed to demonstrate benefit (25).

Therefore, it is suggested that the selective and lethal pulmonary thromboembolism progresses under the standard therapies and that novel and more effective therapies are necessary to suppress the excessive action of inflammatory cells and mediators and the progression of the pulmonary thromboembolism in 


\section{Pulmonary Thrombosis in DIC with Sepsis}

sepsis-induced DIC.

\section{References}

1) Baker WF Jr. Clinical aspects of disseminated intravascular coagulation: a clinician's point of view. Semin Thromb Hemost 15: 1, 1989.

2) DeLee JB. A case of fatal hemorrhagic diathesis with premature detachment of the placenta. Am J Obstet 44: 785, 1901.

3) Müller-Berghaus G. Pathophysiologic and biochemical events in disseminated intravascular coagulation: Dysregulation of procoagulant and anticoagulant pathways. Semin Thromb Hemost 15: 58, 1989.

4) Rapaport SI, Rao LVM. The tissue factor pathway: How it has become a "prima ballerina". Thromb Haemost 74: 7, 1995.

5) Hack CE, Thijs LG. The orchestra of mediators in the pathogenesis of septic shock: a review. in: Update in Intensive Care and Emergency Medicine, Vincent JL, Ed. Springer-Verlag NY Inc, New York, 1991, 14: p. 232.

6) Thomas L, Good RA. Studies on the generalized Shwartzman reaction. I. general observations concerning the phenomenon. J Exp Med 96: 605, 1952.

7) Horn RG. Evidence for participation of granulocytes in the pathogenesis of the generalized Shwartzman reaction. A review. J Infect Dis 128: Suppl: 134, 1973.

8) Bellomo R. The cytokine network in the critically ill. Anaesth Intensive Care 20: 288, 1992.

9) Bone RC. Modulators of coagulation: a critical appraisal of their role in sepsis. Arch Intern Med 152: 1381, 1992.

10) Edwards RL, Rickles FR. The role of leukocytes in the activation of blood coagulation. Semin Hematol 29: 202, 1992.

11) Okajima K, Yang WP, Okabe H, Inoue M, Takatsuki K. Role of leukocytes in the activation of intravascular coagulation in patients with septicemia. Am J Hematol 36: 265, 1991.

12) Klebanoff SJ, Vadas MA, Harlan JM, et al. Stimulation of neutrophils by tumor necrosis factor. J Immunol 136: 4220, 1986.

13) Bick RL. Disseminated intravascular coagulation. Objective laboratory diagnostic criteria and guidelines for management. Clin Lab Med 14: 729, 1994.
14) Kastumura Y, Ohtsubo K. Incidence of pulmonary thromboembolism, infarction and haemorrhage in disseminated intravascular coagulation: a necroscopic analysis. Thorax 50: 160, 1995.

15) Salgado A, Boveda JL, Monasterio J, et al. Inflammatory mediators and their influence on haemostasis. Haemostasis 24: 132, 1994.

16) Guthrie LA, McPhail LC, Henson PM, Johnston RB Jr. Priming of neutrophils for enhanced release of oxygen metabolites by bacterial lipopolysaccharide. Evidence for increased activity of the superoxideproducing enzyme. J Exp Med 160: 1656, 1984.

17) Koga S, Okajima K, Okabe H, Inoue M, Takastuki K. Superoxide production of polymorphonuclear leukocytes in disseminated intravascular coagulation. in: Medical, Biochemical and Chemical Aspects of Free Radicals. Hayaishi O, Niki E, Kondo M, Yoshikawa T, Eds. Elsevier, Amsterdam, 1989, p. 1327.

18) Abe H, Okajima K, Okabe H, Takatsuki K, Binder BR. Granulocyte proteases and hydrogen peroxide synergistically inactivate thrombomodulin of endothelial cells in vitro. J Lab Clin Med 123: 874, 1994.

19) Colman RW. The role of plasma proteases in septic shock. N Engl J Med 320: 1207, 1989 (editorial).

20) Plow EF. Leukocyte elastase release during blood coagulation. A potential mechanism for activation of the alternative fibrinolytic pathway. $\mathbf{J}$ Clin Invest 69: 564, 1982.

21) Windsor ACJ, Mullen PG, Fowler AA, Sugerman HJ. Role of the neutrophil in adult respiratory distress syndrome. Br J Surg 80: 10, 1993.

22) Mulligan MS, Varani J, Dame MK, et al. Role of endothelial-leukocyte adhesion molecule 1 (ELAM-1) in neutrophil-mediated lung injury in rats. J Clin Invest 88: 1396, 1991.

23) Newman W, Beall LD, Carson CW, et al. Soluble E-selectin is found in supernatants of activated endothelial cells and is elevated in the serum of patients with septic shock. J Immunol 150: 644, 1993.

24) Okajima K, Fujise R, Motosato Y, Ushijima M, Okabe H, Takatsuki K. Plasma levels of granulocyte elastase-alpha1-proteinase inhibitor complex in patients with disseminated intravascular coagulation: Pathophysiologic implications. Am J Hematol 47: 82, 1994.

25) Quezado ZM, Banks SM, Natanson C. New strategies for combatting sepsis: The magic bullets missed the mark ... but the search continues. Trends Biotechnol 13: 56, 1995. 